\section{Máquinas de ver, modos de ser: visibilidade e subjetividade \\ nas novas tecnologias de informação e de comunicação*}

\section{RESUMO}

O presente artigo fala sobre a relação entre subjetividade e visibilidade que ganha novos contornos com as tecnologias comunicacionais contemporâneas. Tais tecnologias participam de uma transformação no modo como os indivíduos constituem a si mesmos e modulam sua identidade a partir da relação com o outro, mais especificamente com o 'olhar' do outro.

\section{ABSTRACT}

This article deals with the relationship betwen subjectivity and visibility and the role played by the new com-munication technologies on this matter.

\section{PALAVRAS-chaVe (KaY WORDS)}

- Subjetividade (Subjectivity)

- Tecnologias (Technologies)

- Contemporaneidade (Contemporaneity)

Fernanda Bruno**

UFRJ/Brasil

\section{"A visibilidade é uma armadilha"} Michel Foucault
A RELAÇÃO ENTRE subjetividade e visibilidade ganha novos contornos com as tecnologias comunicacionais contemporâneas. Tais tecnologias participam de uma transformação no modo como os indivíduos constituem a si mesmos e modulam sua identidade a partir da relação com o outro, mais especificamente com o 'olhar' do outro. De um lado, weblogs e webcams promovem novos formatos de exposição da vida íntima e privada $^{1}$. De outro lado, circuitos internos de TV, câmeras, chips, bancos de dados e programas computacionais de coleta e processamento de informação expõem as ações e comportamentos de inúmeros indivíduos a uma vigilância quase que contínua. Estes novos dispositivos dão continuidade a uma tendência inaugurada na modernidade: a incidência do foco de visibilidade sobre o indivíduo comum, aspecto decisivo na produção de subjetividades e identidades. No interior desta continuidade pretendese, contudo, apreender dois deslocamentos principais. O primeiro concerne à constituição de uma subjetividade exteriorizada e marcada pela projeção e antecipação, que vem se sobrepor a uma subjetividade interiorizada e marcada pela introspecção e pela hermenêutica. $\mathrm{O}$ segundo diz respeito a mudanças no estatuto do olhar do outro e do observador, que assume duas novas formas: a primeira, própria aos weblogs e webcams, é caracterizada pela privatização do olhar outrora público e coletivo; a segunda, 
própria à vigilância eletrônica, é caracterizada pelo primado da 'pre-visão' sobre a visão. Os weblogs e webcams ${ }^{2}$ serão ainda explorados tendo em vista as mudanças no sentido e na experiência da intimidade, que deixa de corresponder à tópica moderna do sujeito, onde se opunha aparência e realidade vinculando a primeira à superfície, à exterioridade e à máscara e a segunda à profundidade, à interioridade e à verdade.

Antes de explorar as transformações anunciadas, cabe explicitar os nexos entre subjetividade, visibilidade e tecnologia. Nos restringiremos a mostrar como estes três domínios se imbricam na modernidade para em seguida traçarmos os deslocamentos engendrados na atualidade. A referência a Foucault é indispensável. Em sua "genealogia da alma moderna" (1983, p. 31), uma das definições do projeto de Vigiar e Punir, a subjetividade é inseparável dos dispositivos de visibilidade. As instituições disciplinares, que encontram seu modelo ideal no Panóptico, são máquinas de ver que produzem modos de ser. $\mathrm{O}$ poder disciplinar e a produção de individualidades e subjetividades na modernidade não podem ser dissociados de todo um jogo de olhares e de uma "arte obscura da luz e do visível" (idem, p. 154), presentes nos diversos dispositivos e tecnologias, mais ou menos materiais, que constituem o mecanismo disciplinar. De construções arquitetônicas a discursos e táticas, constitui-se "um aparelho onde técnicas que permitem ver induzem a efeitos de poder, e onde, em troca, os meios de coerção tornem claramente visíveis aqueles sobre quem se aplicam" (idem, p. 153). Aí reside uma das principais características da tecnologia disciplinar e sua diferença em relação ao modelo de poder que a precede, baseado na soberania: a inversão do foco de visibilidade no exercício do poder. O olhar não mais incide naqueles que exercem o poder, mas naqueles sobre quem o poder é exercido. Sobre o indivíduo comum, ordinário, e ainda mais sobre aqueles que estão aquém do comum e mediano - o desviante, o anormal. Trata-se, de fato, de um olhar individualizante, de um poder que individualiza pelo olhar, tornando visível, observável, analisável, calculável o indivíduo comum. Deste modo, o poder torna-se cada vez mais anônimo enquanto o indivíduo comum ou desviante, exposto à visibilidade, torna-se cada vez mais objetivado e atrelado a uma identidade - o criminoso, o doente, o louco, o aluno, o soldado, o trabalhador têm seus comportamentos, sintomas, manias, vícios, falhas, desempenhos, aptidões, méritos e deméritos investidos, conhecidos, registrados, classificados, recompensados, punidos por uma maquinaria de vigilâncias hierarquizadas.

Vejamos com mais detalhes de que modo tal exposição à visibilidade produz indivíduos e subjetividades. Lembremos dos princípios que regem o Panóptico de Bentham, o conhecido dispositivo arquitetônico de vigilância, "máquina ótica universal das concentrações humanas" (Miller, 2000, p. 77), polivalente em suas aplicações: prisão, escola, hospital, fábrica, asilo psiquiátrico. A arquitetura circular, as celas individuais dispostas em anel e a torre central atendem ao princípio de dissociação do par ver-ser visto (Foucault, op. cit., p. 178) ou de "repartição do visível e do invisível" (Miller, op. cit., p. 77). Da torre central, onde deve se instalar a vigilância, a transparência é total - todas as celas, todos os indivíduos nelas alojados são perfeitamente visíveis; o olho central tudo vê. Das celas, ou nada se vê ou se é furtado da decisão sobre o que se vê. Lateralmente, nada se vê, pois as celas dispostas em anel são separadas por partições que impedem ver umas às outras. Esta invisibilidade lateral é garantia da ordem: sem visão e comunicação, os indivíduos são mantidos distantes dos complôs, contágios, conluios, violências recíprocas etc. (Foucault, op. cit., p. 177).

No lugar destes fenômenos próprios às aglomerações humanas e às massas, constitui-se uma "coleção de individualidades separadas", "enumerável e controlável" onde os indivíduos reclusos residem numa "solidão seqüestrada e olhada" (ibidem). O lado de 
fora do edifício também é invisível desde a cela - a janela voltada para o exterior deixa entrar o ar e a luz mas impede que se olhe para fora. A torre central é finalmente visível desde a porta da cela voltada para a face interna do anel, mas anteparos impedem que se veja o interior da torre. Deste modo, não é possível decidir se há ou não alguém na torre central. Noutras palavras, não é possível decidir a presença ou ausência do vigia, mas se está constantemente ciente de que sempre se pode ser vigiado. Ao princípio de dissociação do par ver-ser visto - "no anel periférico se é totalmente visto, sem nunca ver; na torre central, vê-se tudo, sem nunca ser visto" (idem, p. 178) - junta-se o de 'inverificabilidade' do poder (ibidem).

Este segundo princípio é decisivo para que se cumpra o que Foucault considera ser o efeito mais importante do Panóptico: "Induzir no detento um estado consciente e permanente de visibilidade que assegura o funcionamento automático do poder" (Idem, p. 177). Na medida em que o recluso não pode verificar se o olho do poder de fato o observa, a vigilância se torna constante e independente da presença real do vigia.

"Se posso discernir o olhar que me espia, domino a vigilância, eu a espio também, aprendo suas intermitências, seus deslizes, estudo suas regularidades, posso despistá-la. Se o Olho está escondido, ele me olha, ainda quando não me esteja vendo" (Miller, op. cit., p. 78$)^{3}$.

Graças a esta astúcia, opera-se uma admirável economia do poder e uma maximização de sua eficácia. Diminuição de custos físicos e financeiros, pois nem mesmo a presença real daquele que exerce o poder é requerida. Aumento de eficácia, pois se garante com isso uma "vigilância permanente em seus efeitos ainda que descontínua em sua ação" (Foucault, op. cit., pp. 177-178). Diminuição dos custos políticos, pois além de reduzir drasticamente a cota de violência e crueldade no exercício do poder, este age discreta e anonimamente, suscitando pouca resistência. Ganho de eficiência, pois os próprios indivíduos, então submetidos à visibilidade, tornam-se a um só tempo o efeito e o instrumento do poder, que passa a funcionar de modo automático e quase espontâneo através daqueles mesmos que visa a sujeitar.

Começa a ficar claro em que medida a exposição à vigilância e à visibilidade produz individualidades e subjetividades. Sabe-se que esta produção não se realiza 'de cima para baixo' nem simplesmente 'de fora para dentro', ou seja, as repetidas vezes em que Foucault (op. cit.) afirma que os indivíduos são ao mesmo tempo o principal efeito e o principal instrumento do poder disciplinar ele está chamando a atenção para o quanto o poder não implica apenas uma relação com o outro, mas também uma relação dos sujeitos consigo mesmos: a vigilância e a autovigilância, o olhar do outro e o olhar sobre si. Se a objetivação dos indivíduos requer a presença do olhar do outro, a vigilância e seus efeitos disciplinares dependem ainda de todo um processo de subjetivação e interiorização. O olhar do outro deve constituir um olhar sobre si, deve abrir todo um outro campo de visibilidade que se situa agora no interior do próprio indivíduo e que deve ser 'observado' por ele mesmo. Essa passagem da vigilância para a autovigilância ${ }^{4}$ supõe um segundo elemento da maquinaria disciplinar: a sanção normalizadora.

Foucault apresenta inicialmente a sanção normalizadora como um "pequeno mecanismo penal” (op. cit., p. 159) que recobre o espaço deixado vazio pela lei jurídica. Os pequenos gestos e atitudes, as tarefas e atividades cotidianas, o tempo, os discursos, os hábitos, a maneira de ser de cada indivíduo etc. - eis sobre o que se abaterá esta micropenalidade que, na realidade, se dirige menos ao que cada um faz do que ao que cada um é. Ou melhor, a norma é aquilo que opera a passagem da ação ao ser, extraindo do comportamento individual o ser, a identidade de cada um. O que se pune é 
a inobservância, o inadequado à regra, o não conforme, o desvio, o anormal, enfim. A norma é uma lei imanente; é uma regularidade observada e um regulamento proposto (idem, 160). Na escola, no exército, na fábrica etc. observa-se o regular, dado pela média dos indivíduos na realização das atividades e tarefas requeridas. Tal regularidade torna-se, na seqüência, uma regra, um regulamento: os que não se ajustam à regra são reprovados, advertidos, punidos. E tal reprovação não concerne apenas ao mau cumprimento de uma atividade, mas ao valor dos indivíduos, lhes conferindo uma identidade - o aluno estúpido, o soldado indisciplinado, o operário indolente.

“[...] Os aparelhos disciplinares hierarquizam, numa relação mútua, os 'bons' e os 'maus' indivíduos. Através desta microeconomia de uma penalidade perpétua, opera-se uma diferenciação que não é a dos atos, mas dos próprios indivíduos." (idem, p. 162)

Esta divisão não encontra sua efetividade enquanto for entendida como algo que se impõe, do exterior, aos indivíduos. A norma, ou bem a classificação dos indivíduos segundo normal/anormal, só funciona, de fato, no interior dos indivíduos e enquanto estes se julgam e se concebem segundo seus valores e parâmetros. A passagem do exterior ao interior implica dois movimentos. Em primeiro lugar, a sanção normalizadora traz à existência a anormalidade personificada - a "classe vergonhosa" (idem, p. 163) da escola, o perverso sexual, a criança onanista, a besta criminosa. Mas esses seres periféricos, essas existências exteriores e marginais, encarnações da anormalidade, constituem também a interioridade dos indivíduos, pois atuam diretamente sobre seus desejos e temores em relação à sua própria natureza e valor, que se orientam segundo a divisão agora interiorizada do normal e anormal. O segundo movimento é portanto o de interiorização e de identificação com o princípio que classifica a natu- reza e o valor dos indivíduos segundo bons e maus, normais e anormais. Esta divisão, uma vez interiorizada, não se dá apenas entre indivíduos mas também no interior de cada um passando a reger a relação consigo. Eis por que a norma opera a passagem da vigilância à autovigilância. Produzindo aquilo que ninguém pode ser, ela orienta o campo de experiências e escolhas sobre o que os indivíduos desejam ser. Através da identificação com os valores que regem a divisão proposta pela norma, os indivíduos passam a temer, neles mesmos e não apenas no outro, o mal ou a anormalidade. Deste modo, a norma passa a ser não tanto imposta, mas até mesmo almejada. Afinal de onde a norma tiraria a sua positividade senão da produção daquilo mesmo que ela vem negar - de onde, por exemplo, uma sexualidade regular e conforme aos limites da genitalidade poderia retirar seu mérito senão da existência do perverso como a encarnação de uma alma doente com paixões repulsivas?

Por meio do duplo movimento acima descrito, dá-se um duplo efeito. De um lado, a sujeição ao olhar do outro encontrase legitimada, e mesmo consentida, quando o outro assume o lugar daquele que deve cuidar e assegurar o bem daqueles por quem vela. De outro, a autovigilância integra a relação, o cuidado que os indivíduos mantêm consigo, com o que desejam ou temem ser, com o que pretendem alcançar ou extirpar de si.

Todo esse jogo de visibilidades e identidades, de olhares e individualidades que marcam a constituição da subjetividade moderna vem se completar com o exame - terceiro elemento do dispositivo disciplinar. Ritual "de verdade", o exame faz a vigilância e o olhar conduzirem não apenas à coerção de comportamentos ou à interiorização da norma, mas principalmente a um conhecimento formalizado sobre os indivíduos. Sabe-se que as instituições disciplinares não são apenas dispositivos de vigilância e normalização, mas também aparelhos de "examinar" e produzir conhecimento: 
o hospital, o asilo psiquiátrico, a escola, a prisão, a fábrica, são locais onde a assistência médica e terapêutica, a aprendizagem, o confinamento corretivo e a produção permitem levantar um campo de conhecimentos sobre os doentes e a doença física ou mental, sobre o aluno e o desenvolvimento cognitivo, o criminoso e as técnicas de reabilitação, o trabalhador e o processo de produção. Nesta medida, são locais onde os indivíduos caem na objetividade. O indivíduo comum, o homem qualquer torna-se um 'objeto' descritível, mensurável, digno de registro e análise. O olho do poder aí misturado ao olho do saber tem menos o peso de uma força que diz não, que oprime, do que a sutileza de uma técnica positiva que produz a verdade do indivíduo - por meio dessa vigilância examinadora, cada indivíduo torna-se um "caso", com uma biografia, uma identidade, uma individualidade, uma verdade, enfim (idem, p. 170). Neste sentido, o exame é um ritual pelo qual a norma é extraída, produzida, e também é o lugar onde ela se exerce, com todos os seus efeitos. A individualidade e a verdade aí constituídas são interiorizadas pelos indivíduos de modo a serem experimentadas não como algo exterior ou derivado, mas como sua própria verdade.

Nota-se que os três elementos combinados - vigilância, sanção normalizadora e exame - constituem um campo de visibilidade e procedimentos de observação que vão além da superfície dos comportamentos, gestos e atividades para ingressar na interioridade, tornando pensamentos, desejos e paixões também sujeitos à observação e à vigilância. Eis por que a disciplina é para Foucault uma tecnologia de poder que atua sobre o corpo mas que visa, sobretudo, a alma. Ou melhor, a alma moderna, seja que nome ou conceito lhe tenha sido atribuído - psiquismo, subjetividade, consciência -, é mesmo o efeito, o desdobramento incorpóreo, porém extremamente real, deste mecanismo disciplinar de adestramento, vigilância e observação dos corpos (idem, p. 29). Nesta medida, os dispositivos de visibilidade modernos fundam uma subjetividade que deve aplicar sobre si mesma, no recolhimento de sua interioridade, os procedimentos de observação e correção que lhes são aplicados do exterior.

dispositivo disciplinar consegue assim, na sua forma ideal, lançar luz sobre aquilo que de outro modo restaria na sombra e na invisibilidade, o que, para esta forma de poder, pode ser um meio de proteção e resistência. Como vimos, a autovigilância só se cumpre a partir da identificação com o olho do poder, representante da norma, e sua respectiva interiorização.

Apenas assim

“(...) quem está submetido a um campo de visibilidade, e sabe disso, retoma por sua conta as limitações do poder; fá-las funcionar espontaneamente sobre si mesmo; inscreve em si a relação de poder na qual ele desempenha simultaneamente os dois papéis... [Deste modo] não é necessário recorrer à força para obrigar o condenado ao bom comportamento, o louco à calma, o operário ao trabalho, o escolar à aplicação, o doente à observância das receitas" (idem, p. 179).

É claro que a almejada visibilidade interior, engendrada na relação dos indivíduos consigo mesmos, ultrapassa a dimensão ótica e exige procedimentos hermenêuticos que devem a um só tempo trazer à luz o que impede a adequação à norma e promover uma transformação no indivíduo, na sua interioridade, que garanta esta adequação: reforma, correção. Apenas nesta medida que se pode compreender todo o processo de transformação dos indivíduos previsto na máquina panóptica. À visibilidade é preciso somar uma dose de sofrimento, fundamental para a requerida reforma que deve ser, mais do que dos corpos e comportamentos, da própria alma. E o próprio sofrimento também deve encontrar sua sede não mais no corpo e sim na alma: a culpa. Fazer sofrer a alma, e não o corpo - eis a 
lógica de um poder que em vez de negar e reprimir uma individualidade ou subjetividade constituídas constitui uma subjetividade que julga e condena a si mesma. Ora, o sofrimento da alma é menos o de uma consciência reprimida do que o de uma consciência culpada, de uma má-consciência, cuja dor só é efetiva e corretiva enquanto derivar de uma falha, um mal atribuído a si mesmo e não ao outro. É também nesta medida que se deve entender a célebre frase que condensa o funcionamento e o efeito desejados pelo panóptico - dar "ao espírito poder sobre o espírito" (idem, p. 182). Ou a referência que Foucault faz a Julius em sua descrição do panóptico - "bem mais que um talento arquitetural: um acontecimento na 'história do espírito humano'" (idem, 190). Acontecimento que marca, como vimos, a gênese da subjetividade moderna, que pode também ser entendida como a gênese da má-consciência moderna.

Espera-se, com esta breve análise do dispositivo disciplinar, ter esclarecido o quanto a subjetividade e o 'espírito' moderno são ao mesmo tempo os efeitos e os portadores de um poder que tem entre suas principais técnicas a exposição do indivíduo comum à visibilidade. Tal exposição ganha continuidade na passagem da modernidade para a atualidade, se vista sob a perspectiva das tecnologias de comunicação. É claro que esta continuidade não implica a repetição do que se passa na modernidade. As tecnologias de comunicação constituem novos dispositivos de visibilidade com diferentes implicações na sociedade e na subjetividade.

Se considerarmos a trajetória destas tecnologias, desde a TV até a Internet, e a compararmos ao modelo panóptico, apreenderemos uma série de inversões, desvios e deslocamentos na relação entre indivíduo e visibilidade. São conhecidos os argumentos de que o advento dos meios de comunicação de massa, particularmente a TV, implica a emergência de um novo dispositivo de poder e vigilância onde muitos vigiam poucos, diferentemente do modelo panóptico, onde poucos vigiam muitos (cf. Bauman, 1999). Este novo dispositivo, a que Mathiesen (1997, apud Bauman, op. cit., p. 60) chama Sinóptico, promoveria mais uma vez a inversão do foco de visibilidade no exercício do poder: ele deixa de incidir sobre o indivíduo comum, ordinário, e volta a investir naqueles que detêm o poder, as elites, constituindo uma nova fase do espetáculo onde brilham não mais os reis e a corte, mas celebridades e pop stars do mundo televisivo. O indivíduo comum, a massa, passa à condição de observador de uns poucos dignos de visibilidade, deixando de ser objeto de coerção ou correção para se tornar alvo de um poder que se exerce sobretudo por sedução. Tal argumento é sem dúvida pertinente às formas atuais da relação entre o poder, os dispositivos de visibilidade e os indivíduos. No entanto, tal relação vem recentemente ganhando novos contornos tanto no interior da própria TV quanto nas novas tecnologias de comunicação e de informação, como a Internet e os diversos dispositivos que vigoram no ciberespaço.

Em L'individu incertain, Alain Ehrenberg (1995) mostra brilhantemente como o indivíduo qualquer e a banalidade de sua existência e de seus problemas pessoais ingressam no reino televisivo. O crescente aumento de programas de caráter confessional e 'realista' coloca os holofotes sobre o indivíduo e sua realidade ordinária, seus problemas psíquicos, conjugais, pessoais ${ }^{5}$. Tais espetáculos de realidade ganham ainda mais espaço nos formatos recentes dos 'reality shows' como Loft Story e Big Brother. Não se quer apontar com isso o fim do espetáculo das celebridades e sua substituição pelo espetáculo de realidade. Sabe-se que estes dois formatos convivem e se alimentam reciprocamente, ainda que constituam dois modos distintos de espetáculo e de relação com o espectador. O que desejamos ressaltar é o retorno do foco de visibilidade sobre o indivíduo comum, agora residente não mais nas instituições disciplinares, mas nas telas de TV. E não apenas aí - as novas tecnologias de comunicação e de informa- 
ção ampliam ainda mais esta tendência: os circuitos internos de tv e câmeras dispostos sobre espaços públicos e privados, os chips, os bancos de dados eletrônicos e programas computacionais de coleta e processamento de informação no ciberespaço e os recentes fenômenos dos weblogs e webcams na Internet constituem um novo campo de visibilidade para o indivíduo comum.

Este novo campo de visibilidade, objeto do nosso interesse, comporta duas características relevantes: a vigilância e a exposição da vida íntima e privada. Câmeras de circuito interno, chips informáticos e bancos de dados eletrônicos vêm sendo descritos, por diversos autores, como peças de um aparato global de vigilância, uma espécie de superpanóptico, que não mais se restringe aos espaços fechados das instituições mas se estende tanto sobre dimensões alargadas do espaço físico quanto sobre o ciberespaço, ampliando enormemente o número de indivíduos sujeitos à vigilância e à capacidade de coleta, processamento e uso de informações a seu respeito (cf. Lyon, 1994 e 2003; Poster, 1995; Bogard, 1996, Norris \& Armstrong, 1999; Marx, 2002). Webcams e weblogs, por sua vez, têm sido explorados como novas formas de exposição de si (Lemos, 2002; Sibilia, 2003; Mcneil, 2003; Garza, 2002; Zuern, 2003) que abalam as fronteiras entre público e privado ao encenarem no âmbito público da Internet práticas antes restritas à vida íntima (imagens do espaço privado cotidiano, escrita de diários íntimos). Se podemos ver nas características ressaltadas alguma continuidade em relação ao que descrevemos da modernidade, também é possível apreender uma série de descontinuidades.

Uma primeira descontinuidade concerne ao modo como estes dispositivos de vigilância e de visibilidade participam do processo de constituição da subjetividade contemporânea. Se os dispositivos modernos escavavam uma subjetividade interiorizada $^{6}$ que instaurava de si para consigo, pela introspecção ou pela hermenêutica, uma autovigilância que de algum modo continuava o olhar do Outro e a norma por ele representada, os dispositivos contemporâneos vêm contribuir para a constituição de uma subjetividade exteriorizada onde vigoram a projeção e a antecipação. Exteriorizada porque encontra na exposição 'pública', ao alcance do 'olhar', escrutínio ou conhecimento do outro, o domínio privilegiado de cuidados e controle sobre si. Nos weblogs de caráter 'confessional' e nas webcams pessoais esta exteriorização é patente. É importante notar que não se trata tanto da exteriorização de uma interioridade constituída, por natureza recôndita, que passa a se expor, mas principalmente de uma subjetividade que se constitui prioritariamente na própria exterioridade, no ato mesmo de se projetar e de se fazer visível a outrem. Depoimentos de diaristas e estudos sobre webcams e a escrita de si na Internet mostram como a prática da exposição de si coincide com o processo de constituição do que os indivíduos tomam como seu 'eu' e sua identidade 7 .

Quanto aos referidos dispositivos de vigilância contemporâneos, o caráter exteriorizado da subjetividade não é tão imediatamente visível, mas ainda assim presente. Não ser imediatamente visível toma aqui um sentido quase literal, ou seja, os indivíduos sob vigilância no ciberespaço, particularmente nos bancos de dados eletrônicos, não são num primeiro momento pessoas com uma identidade, uma personalidade que se conheça de antemão. Esta identidade vai ser 'composta' num segundo momento, através do processamento e do cruzamento de um conjunto de dados e informações inicialmente impessoais - 'populações', 'categorias', 'contextos'. Destas categorias, constituídas em função de espaços geográficos, períodos de tempo, faixa etária, hábitos de consumo, dados biológicos, genéticos, criminais etc., é que se vai projetar, antecipar indivíduos a serem pessoalmente vigiados, cuidados, punidos ou seduzidos. A subjetividade é aí exteriorizada na medida em que o que a caracteriza, o que a 'constitui' e a 'compõe' são menos intenções, desejos, 
paixões e inclinações reclusas numa interioridade, num psiquismo que deve ser interpretado e trazido à luz, do que um campo superficial de ações, comportamentos, hábitos e transações eletrônicas dispostos em bancos de dados que, uma vez analisados e classificados, irão projetar criminosos, consumidores, doentes, trabalhadores, atuais ou potenciais. É da exterioridade da ação e do comportamento que se extrai ou se projeta a subjetividade, com uma identidade e uma individualidade que não estavam previamente presentes. $\mathrm{O}$ ato de vigilância não se dá sobre um indivíduo já constituído; ele projeta, antecipa um indivíduo e uma identidade potencial ${ }^{8}$.

Ora, vimos que o caráter individualizante da vigilância também é um dos traços centrais do panóptico e do poder disciplinar, sendo o indivíduo o seu principal efeito e instrumento. Certamente, tanto os atuais dispositivos de vigilância quanto os modernos produzem indivíduos, mas na modernidade o indivíduo está presente desde o início do processo de vigilância e ainda que esta venha a constituir ou transformar sua identidade, a presença física do louco, do criminoso, do perverso, do doente é desde o início requerida. E o que faz deles esses seres marginais e anormais é o peso de uma história familiar, a força insistente de impulsos inconscientes, uma intrincada e obscura causalidade psicológica, uma trama complexa de desejos, inclinações que vêm determinar, do interior em sombra, uma série de ações, comportamentos e hábitos exteriores e visíveis. Eis por que, como se mostrou, a vigilância moderna deve ver e agir através, sob a superfície dos corpos e comportamentos de modo a incidir sobre a interioridade, a alma dos indivíduos. $\mathrm{Na}$ atualidade, trata-se sobretudo de ver adiante, de prever e predizer, a partir dos cruzamentos e análises de dados, indivíduos e seus atos potenciais, seja para contê-los (como no caso de crimes, doenças, onde tende a predominar uma vigilância preventiva), seja para incitá-los (como no caso do consumo, da publicidade e do marketing).
O ritual do exame e seus procedimentos hermenêuticos são substituídos pelos perfis computacionais e seus procedimentos algorítmicos e estatísticos.

Os indivíduos e identidades, projetados e antecipados pelos atuais dispositivos de vigilância, não interessam para além do campo exterior dos comportamentos atuais e potenciais. Cada vez menos importa o que reside sob ou na interioridade destes indivíduos. Tanto a definição de sua identidade quanto as intervenções visadas não vão além do campo de ações e comportamentos destes indivíduos. Nota-se aqui mais uma diferença em relação à modernidade: a incidência de visibilidade sobre o indivíduo não quer curar ou reformar o criminoso, o doente físico ou mental, mas sim impedir o crime, prevenir a doença ou minimizar seus riscos. Ou seja, o foco de intervenção não é mais a alma, a interioridade, o psiquismo, mas o comportamento, o campo de ações exteriores e visíveis. Alguns exemplos podem esclarecer o que se quer mostrar. As câmeras que visam a manter a segurança de lugares públicos ou privados atuam sobre o crime, impedindo a ação, e não sobre o criminoso, como queria a vigilância panóptica. $\mathrm{Na}$ psiquiatria, a dificuldade em se definir um critério de normalidade constitui uma tendência a substituir o ideal da cura por procedimentos terapêuticos que se voltem para a diminuição do sofrimento e dos riscos da doença mental para o paciente e seus familiares (cf. Castel, 1981).

A segunda descontinuidade a ser ressaltada concerne ao estatuto do 'olhar' do outro e do observador e seu papel na constituição de subjetividades e identidades. Vejamos primeiro o caso das webcams e dos weblogs: a exposição ao olhar e à observação do outro é aqui um ato voluntário e decisivo como prática identitária. O estatuto deste outro ainda não está claro e merece uma análise muito mais aprofundada do que a que este artigo pode efetuar. No entanto, o contraste com a modernidade contribui para que arrisquemos algumas hipóteses que, apesar de provisórias, merecem ser 
consideradas. Uma primeira hipótese é a de que o olhar do outro deixa de ser dado pelo coletivo, pela sociedade e passa a ser demandado, conquistado pelo próprio indivíduo. Em outros termos, o olhar do outro é 'privatizado', individualizado. Vimos como o olho central do Panóptico representava o olho do poder normalizador; a indecidibilidade acerca de sua presença real e a sua almejada interiorização pelos indivíduos constituíam o ardil que garantia o funcionamento automático do poder. Ora, o olho central é o olho de Deus laicizado, é o grande olho público, o olhar do outro onde se inscreve a ordem social e coletiva com suas normas e leis, anteriores a qualquer indivíduo e da qual ninguém está plenamente livre. Segundo o diagrama moderno, não há indivíduo e identidade que se constituam fora deste olhar, ainda que se lhe possa resistir ou opor num segundo momento. $\mathrm{O}$ pertencimento necessário a um coletivo, a uma instituição, ao olhar do outro, enfim, garantia o processo identitário.

Hoje, este olhar público e coletivo parece não mais estar dado, precisando ser produzido pelos próprios indivíduos. As práticas de exposição de si na Internet podem ser vistas neste sentido como uma demanda pelo olhar do outro, que se torna assim uma conquista individual, privada e não mais um dado público. Esta hipótese só faz sentido no interior de um cenário de individualização da existência e radicalização da responsabilidade por si mesmo nos diversos setores da vida privada e pública contemporâneas, da progressiva privatização das trajetórias individuais e do paralelo declínio do encargo coletivo dos destinos individuais, antes atribuído a instituições e atores sociais organizados (cf. Bauman, op. cit., e Ehrenberg, op. cit.). Já é bastante conhecida a progressiva 'privatização' de domínios antes vinculados a projetos públicos, como a saúde, a formação, o trabalho etc. Os weblogs e webcams apontam para a individualização e 'privatização' do que parecia público quase que 'por natureza' - o olhar do outro, que se torna aí uma responsabili- dade do próprio indivíduo.

Num mesmo golpe, estas práticas efetuam o movimento inverso de publicização do que antes soava 'naturalmente' privado: a intimidade. Mais um contraste com a modernidade, que auxilia a compreender o papel do olhar do outro na constituição da identidade e da subjetividade contemporâneas. Quando o olhar do outro, do coletivo está dado, tal como na modernidade, a intimidade, a interioridade, ainda que sejam atravessadas por ele, ocupam muitas vezes o lugar do segredo, do recolhimento, da verdade que em alguma medida pode escapar à observação alheia ${ }^{9}$. Daí a intimidade e a interioridade, enquanto domínios privados, serem muitas vezes associadas à liberdade, ao que pode resistir ao olhar normalizador do coletivo e à luz da opinião pública, fazendo falhar a máquina panóptica (cf. Corbin, 1991). Daí também uma tópica do sujeito que associa a aparência à superfície, à exterioridade e à mascara e a realidade à profundidade, à interioridade e à verdade. Esta tópica ajusta-se perfeitamente à sociedade moderna, que estabelece limites claros entre o público e o privado. A crise destes limites, encenada nos weblogs e webcams, subverte esta tópica e transforma o sentido da intimidade e da interioridade. Estes dois domínios, antes constantemente ameaçados de uma visibilidade 'seqüestrada' pelo olho do poder, passam a requerer e produzir sua própria visibilidade. Na ausência do grande olho público, a intimidade se volta para fora, como que em busca de um olhar que a reconheça e lhe atribua sentido, existência. A exposição de si na Internet configura, na seqüência dos reality shows, todo um campo de cuidados com a "aparência interior" (Ehrenberg, op. cit.). O foro íntimo deixa de ser experimentado como o refúgio mais autêntico e secreto para se tornar uma matéria artificialmente assistida e produzida na presença explícita do olhar do outro. Obscenidade, superficialidade e vitória da aparência sobre a realidade e a verdade? Tais acusações perdem força na medida em que a tópica que as justifica não parece mais 
delimitar a experiência contemporânea de si e do outro. Nos weblogs pessoais, webcams e reality shows, pouco importa a distinção aparência/realidade - a verdade é o que se mostra, pois não reside numa interioridade prévia e mais autêntica, mas é produzida no ato mesmo de se mostrar.

Para que estas transformações na intimidade fiquem mais claras, é preciso acrescentar à crise das fronteiras entre o público e o privado e entre a interioridade e a exterioridade duas outras crises, que incidem sobre as fronteiras entre natural/artificial e normal/patológico. Estas duas últimas crises dispensam maiores detalhes. É bastante conhecida a crescente produção de seres híbridos e práticas que não mais respeitam os limites entre natureza e artifício, assim como a flexibilização dos limites que separavam o normal e o patológico no campo dos comportamentos, desejos e modos de vida. O que se deseja ressaltar é o quanto a intimidade também é atravessada por este deslocamento de fronteiras. $\mathrm{O}$ alargamento dos limites do que se pode dizer e fazer em público vai de par com um relaxamento dos critérios de 'normalidade', assim como a produção tecnicamente assistida de si mesmo vai de par com a indefinição dos limites entre natureza e artifício.

Do mesmo modo que o silicone participa da construção artificial do corpo, que os antidepressivos assistem artificialmente a saúde psíquica, os reality shows, weblogs e webcams apresentam-se como dispositivos de produção artificial do foro íntimo e da identidade. Do mesmo modo que não se pode afirmar que o corpo e a experiência que se faz dele tornam-se menos verdadeiros com o silicone, ou que o bem-estar psíquico é menos autêntico sob o efeito de antidepressivos, não se pode afirmar que a intimidade construída na artificialidade das tecnologias de comunicação seja menos autêntica e verdadeira. Todos esses instrumentos e dispositivos assistem o indivíduo contemporâneo para o qual uma nova norma a ser cumprida parece ser a da autonomia e da responsabilidade por si mesmo.
Como aponta Ehrenberg (op. cit., p. 306), a identidade é tão mais uma questão quanto mais se é responsável por si e proprietário de seu corpo. E se tais instrumentos servem à ampliação da visibilidade do indivíduo comum é porque esta deixa de ser uma armadilha que pode aprisionar - como no caso do poder disciplinar - para se afirmar como condição almejada de existência e de reconhecimento. "A convocação de um outro que nos olhe é um recurso para sair do fechamento privado; ela dá uma consistência às realidades psíquicas e as autentifica". (idem, p. 251). Não que a visibilidade antes fosse má e agora seja boa; com Foucault aprendemos que o poder não é bom nem mau, mas aquilo mesmo que divide os indivíduos, a experiência, os desejos segundo bem e mal. Os dispositivos de visibilidade atuais oferecem o olhar do outro e uma cena pública numa realidade social onde o indivíduo só existe se ele é capaz de fazer saber que ele existe (idem). Não por acaso, as tecnologias de comunicação são instrumentos privilegiados na atual constituição da individualidade e da subjetividade.

Talvez desde os meios de comunicação de massa a entrada no campo do visível equivale à entrada no mundo comum onde o necessário reconhecimento pelo outro dignifica e autentifica a existência individual. A exposição de si na Internet constitui um segundo passo nesta demanda por visibilidade na medida em que esta se desconecta do pertencimento ao mundo extraordinário da fama, do sucesso e da celebridade para se estender ao indivíduo qualquer, naquilo mesmo que ele tem de mais ordinário e banal. Como aponta Lemos, neste novo meio "a máxima é: 'Minha vida é como a sua, logo, se tranqüilize, estamos todos na banalidade do quotidiano'" (op. cit., p. 10). Segundo Ehrenberg, a propósito dos reality shows, a visibilidade se torna uma espécie de direito requerido e corresponde a uma mutação no imaginário igualitário onde "o aumento do sentimento de ser igual, malgrado as desigualdades reais, permite investir sobre o indivíduo qualquer, inteiramente seme- 
lhante ao telespectador qualquer, o estilo de identificação que era privilégio dos heróis da cultura de massa" (op. cit., p. 185). A exposição de si na Internet estende ainda mais a visibilidade ao indivíduo comum se comparada aos reality shows televisivos, onde a entrada do 'qualquer $\mathrm{um}^{\prime}$ ainda é centralizada. Com os weblogs e webcams passamos da tentativa de ingresso na mídia para a possibilidade de o indivíduo ser sua própria mídia e criar, conseqüentemente, o seu próprio público ${ }^{10}$.

No entanto, nem toda visibilidade é almejada e requerida. Os dispositivos eletrônicos de vigilância representam muitas vezes a face negativa e potencialmente perversa da visibilidade, inspirando temores de atentados à privacidade e à liberdade dos indivíduos. O olhar do outro e o estatuto do observador assumem outras formas nestes dispositivos. Em primeiro lugar, a vigilância eletrônica representa, segundo inúmeras análises, a diminuição relativa da centralidade da visão e do olhar (cf. Lyon, op. cit., Bogard, op. cit., e Marx, op. cit.). Em vez da demanda pelo olhar dos weblogs e webcams, a economia do poder na vigilância eletrônica parece prescindir do olhar e da presença visível do observador e do observado. As informações coletadas e registradas nas transações eletrônicas, nas redes de comunicação e nos bancos de dados estão menos sujeitas ao olhar que ao tratamento estatístico e informático. Os dados não são em si mesmos nem muito reveladores nem facilmente acessíveis aos sentidos nus, pois além de serem extremamente numerosos, são fragmentados e não compõem um indivíduo a ser apreendido pelo olhar; como vimos, estes indivíduos só emergem num segundo momento graças às técnicas de composição de perfis computacionais. Como a vigilância contemporânea é em sua maioria efetuada a distância, o anonimato e a invisibilidade do observador crescem ainda mais em relação à modernidade, assim como aumentam o seu caráter híbrido. Tais características permitem que a coleta de informações pessoais não seja contida nem por limites naturais, como distância, opacidade, pele, tempo, tamanho, nem por antigos limites construídos, como paredes, cofres, envelopes etc. (Marx, op. cit.). Se na modernidade a vigilância precisava de algum modo imobilizar os indivíduos nos espaços fechados das instituições, hoje é a mobilidade que se oferece ao monitoramento. Além disso, diminui drasticamente a consciência dos vigiados acerca da vigilância; muitas vezes um possível observador nem mesmo é claramente suposto pelo observado. $O$ fato de a vigilância estar hoje intimamente vinculada à troca de informações, às ações e movimentos cotidianos dos indivíduos, juntamente com a 'redução' destes às informações que eles produzem e acessam, os tornam quase que continuamente expostos e muitas vezes inconscientes desta exposição. É claro que numa certa medida todos nós sabemos que podemos estar sendo vigiados, mas esse 'saber' é muito abstrato se comparado à modernidade, onde a vigilância estava vinculada a espaços de reclusão delimitados e onde a consciência da vigilância, associada a sua inverificabilidade, eram fundamentais para que seus efeitos fossem cumpridos.

O campo de ações cotidianas e comportamentos dos indivíduos torna-se hoje mais facilmente rastreado na medida em que muitas vezes coincide com os próprios sistemas de coleta, registro e distribuição de informações. Quando faço um exame médico, por exemplo, estou simultaneamente cuidando de minha saúde e fornecendo informações ao meu seguro de saúde que podem, apesar dos entraves legais, ser apropriadas por outros setores de informação. Quando efetuo uma compra com cartão de crédito, estou simultaneamente realizando um desejo pessoal e fornecendo informações que podem servir a diversos bancos de dados. Esta 'coincidência' entre as ações e comportamentos individuais e a coleta, registro e distribuição de informações amplia enormemente o alcance e a eficiência da vigilância, a ponto de ser possível caracterizar as sociedades informacionais como 
sociedades de vigilância (Lyon, op. cit.). A coincidência entre o campo de ações e comportamentos individuais e os sistemas globais de informação promove ainda uma outra forma de confusão entre o público e o privado, distinta daquela que vigora nos weblogs e webcams. A vida privada e íntima é aqui exposta à visibilidade não por um desejo deliberado do indivíduo, mas pelo fato de suas ações em esferas públicas ou semipúblicas se converterem facilmente e quase que imediatamente em dados e informações que concernem à esfera íntima e privada (dados biográficos e biométricos, desejos e preferências pessoais etc.) sem que o indivíduo tenha o controle sobre estas fronteiras (Lyon, op. cit., Poster, op. cit.).

Que papel sobre a subjetividade e a identidade pode ter um observador sem rosto e sem nome, tão maquínico quanto humano, muitas vezes ignorado pelos indivíduos sob vigilância? Certamente não se pretende responder plenamente a esta pergunta. Consideraremos apenas algumas situações em que a vigilância eletrônica pode ser matéria ou objeto de experiência dos indivíduos e do modo como eles se definem e cuidam de si mesmos. Ressaltaremos, pois, o caráter preditivo e preventivo da vigilância ${ }^{11}$. Uma primeira questão a ser colocada diz respeito aos mecanismos e valores sociais que podem legitimar tal vigilância, desfazendo a sua face conspiratória, monstruosa e ameaçadora em proveito de uma face mais amigável e até desejada pelos indivíduos. Uma possível resposta reside naquilo que nossa sociedade define como sendo o perigo que os dispositivos de vigilância podem evitar. Se na modernidade o perigo residia na anormalidade, no desvio, a atualidade vai fazê-lo residir sobretudo no risco (Cf. Vaz \& Bruno, op. cit.). Em diversos domínios da cultura contemporânea, as preocupações e cuidados em torno da saúde, dos desejos e prazeres, dos modos de vida, do crime, da guerra, da ecologia orientam-se em torno da noção de risco (cf. Castel, op. cit., Douglas, 1992; Rose, 2000). Os exemplos nos são familiares: as preocu- pações em torno da sexualidade estão menos relacionadas à normalidade do ato e da escolha sexual do que aos riscos de doenças sexualmente transmissíveis e de gravidez precoce; o uso de drogas tende a ser tolerado como comportamento e prazer contanto que não ponha em risco a vida do próprio usuário e de outrem ${ }^{12}$; no âmbito da medicina a noção de fator de risco (cf. FagotLargeault, 1989), que indica a probabilidade da ocorrência de um evento mórbido ou fatal, torna-se central incitando uma série de cuidados não tanto com doenças e doentes atuais, tal como na medicina moderna, mas com os riscos (genéticos ou ligados ao ambiente e ao estilo de vida de cada um) de doenças virtuais e de morte prematura (cf. Bruno, 1997); as preocupações com a natureza são hoje em grande parte pautadas pela noção de risco ambiental; a criminologia volta-se menos para o criminoso, as causas (psicológicas, sociais) de seus atos e a reforma de seu caráter do que para a diminuição dos riscos de ocorrência do crime ou de seus efeitos.

A preocupação com o risco em nossa sociedade vai contribuir para 'justificar' uma vigilância que é sobretudo preditiva e muitas vezes preventiva, voltada para a composição de perfis que predigam e prevejam os riscos que assombram os indivíduos. Esta vigilância é tão mais eficiente quanto maior for a identificação dos indivíduos com os perfis projetados (doentes potenciais, vítimas de crimes antecipados, responsáveis por catástrofes naturais potenciais etc.). Deste modo, eles não apenas 'autorizam' a vigilância como a estendem na relação e no cuidado consigo mesmos. Reaparece aqui a hipótese de que a produção de subjetividade é hoje marcada pela antecipação e pela projeção. No entanto, a identificação com os perfis projetados não parece implicar, tal como na modernidade, a interiorização e a reforma da subjetividade. Já se viu o quanto a vigilância informacional e eletrônica não pretende tanto agir sobre a interioridade e reformar a alma dos indivíduos, mas sobre o controle 
dos comportamentos, de modo a prevenir ações indesejadas. A autovigilância torna-se prioritariamente autocontrole. $\mathrm{O}$ operador afetivo em questão é menos a culpa do que a responsabilidade.

Vê-se que os atuais dispositivos de vigilância também são atravessados pela tendência à privatização dos destinos individuais e à individualização da existência, já mencionada na análise dos weblogs e webcams. A vigilância preditiva e preventiva torna-se tão mais 'legítima' quanto mais cada um é suposto responsável pelos riscos próprios ao existir. A vigilância apresentase assim como o que pode assistir o indivíduo na previsão e prevenção de doenças, sofrimentos e demais acontecimentos virtuais. Se nos weblogs assistimos a uma espécie de privatização do olhar do outro, aqui assistimos a uma privatização do futuro na forma da individualização dos riscos.

Cabe observar que nem toda vigilância eletrônica, ainda que seja baseada na predição e na previsão, implica prevenção de riscos. Uma exceção que vale ser mencionada são as esferas do consumo, da publicidade e do marketing, altamente sujeitas à vigilância e também voltadas para a predição de tendências, comportamentos, atitudes, desejos e intenções de consumo a partir de técnicas de cruzamento e análise de informações de diferentes bancos de dados como uma estratégia privilegiada de conquista e sedução de consumidores potenciais. De todo modo, o que está hoje em jogo nas práticas de vigilância eletrônica e no controle dos riscos parece ser menos a reforma dos indivíduos, a ação sobre sua interioridade que a antecipação e a projeção de uma identidade, um perfil composto de comportamentos e ações potenciais que 'autorize' sua inclusão ou exclusão, uso ou descarte, sedução ou marginalização, acesso ou interdição em espaços de consumo, segurança, saúde, formação, trabalho, lazer etc.

Resta perguntar se não tendemos a nos assemelhar aos mutantes precognitivos de Minority Report que, por excesso de 'pre- visão', são como que condenados ao futuro, impedidos de ver o presente, ou simplesmente de viver. E esse é apenas um risco •

\section{Notas}

* Este artigo constitui um resultado do Projeto "As formas híbridas da cognição na atualidade", apoiado pela Fundação Universitária José Bonifácio/FUJB/UFRJ.

** Profa. Adjunta do Instituto de Psicologia da UFRJ - Coordenadora do CiberIDEA/ECO/UFR - Pesquisadora do Programa IDEA/ECO/UFRJ

1 Os interessantes trabalhos de André Lemos (2002) e de Paula Sibilia (2003) sobre weblogs e webcams, apresentados no GT Tecnologias Informacionais de Comunicação e Sociedade/Compós, abriram um campo fértil de problematização com o qual este artigo pretende dialogar e colaborar.

2 A análise de weblogs e webcams se restringe àqueles que têm como conteúdo central a vida íntima e privada.

3 Miller chama a atenção para o quanto este ardil cria uma instância onividente, onisciente e onipresente - uma imitação de Deus ou um Deus artificial (op. cit., pp. 78-79).

4 Para uma análise dos nexos entre vigilância e auto-vigilância em Foucault, Cf. Vaz, P. \& Bruno, F. (2003) "Types of self-surveillance: from abnormality to individuals 'at risk'". In: Surveillance \&Society 1 (3), p. 272-291.

5 Ehrenberg refere-se a programas 'animados' por psicólogos, psicanalistas ou profissionais de comunicação que procuram 'dar voz' ao 'qualquer um' e oferecer alguma orientação e assistência às dificuldades de sua vida pessoal e cotidiana.

6 Sobre a crise da interioridade psicológica no contexto dos diários pessoais divulgados na Internet, cf. Sibilia, 2003.

7 Sobre as webcams e weblogs e o papel da exposição ao olhar do outro na construção da identidade e do vínculo social, cf. Lemos, 2002. $\mathrm{O}$ assunto também é abordado por Mcneil (2003), que enfatiza a atividade do leitor na 'escrita' da identidade construída nos weblogs. 
8 Não se supõe com isso a ausência de uma vigilância disciplinar na sociedade contemporânea. Uma matéria recente na revista Istoé mostra como empresas submetem trabalhadores a uma vigilância panóptica sobre seus e-mails e navegações na Internet, acarretando inclusive demissões. Matéria publicada em 13/08/2003.

9 Sabe-se que ao mesmo tempo em que a modernidade testemunha uma enorme curiosidade pela vida privada, como atesta a intensificação da literatura sobre o tema, as práticas de confissão e de exposição da interioridade usualmente se limitavam ao espaço privado e íntimo. Sobre os procedimentos hermenêuticos de enunciação de si na modernidade, como os diários íntimos e as 'confissões' clínicas, cf. Bruno, F., 1996.

10 Uma declaração da 'bloggeira' Roberta Carvalho, denunciando o caráter inusitado de um plágio de seu weblog, é significativa: "O meu blog é minha vida, e vida todo mundo tem". Declaração feita a programa televisivo da UERJ, emitido pela UTV-Rio no dia 20/01/2004.

11 Uma análise do aspecto preditivo da vigilância atual a partir da noção de simulação, com algumas afinidades e também diferenças em relação à nossa, é efetuada por Bogard, op. cit.

12 Mesmo no Brasil, onde a criminalização do consumo de drogas parece estar longe de ser repensada pelas instâncias governamentais, esta mudança se faz notar numa recente campanha publicitária de prevenção às drogas, onde 0 argumento central de dissuasão é a associação do uso de drogas ao financiamento da violência urbana ligada ao tráfico.

\section{Referências}

BAUMAN, Z. Globalização. Rio de Janeiro: Jorge Zahar, 1999.

BOGARD, W. "The simulation of surveillance: Hypercontrol" In Telematic societies. Cambridge: Cambridge University Press, 1996.

BRUNO, F. "A enunciação de si na Modernidade", In NETO, A. F. \& PINTO, M. J. 0 indivíduo e as mídias. Rio de Janeiro: Diadorim/Compós, 1996.
. Do sexual ao virtual. São Paulo: Unimarco, 1997.

CORBIN, A. "Bastidores", In PERROT, M. (org.) História da vida privada 4: da Revolução Francesa à Primeira Guerra. São Paulo: Companhia das Letras, 1991.

CASTEL, R. La gestion des Risques, de l'anti-psychiatrie à l'aprèspsychanalise. Paris: Minuit, 1981.

DICK, P. K. Minority Report - a nova lei. Rio de Janeiro: Record, 2002.

DOUGLAS, M. Risk and blame: essays in cultural theory. London: Routledge, 1992.

EHRENBERG, A. L'individu incertain. Paris: Calmann-Lévy, 1995

FAGOT-LARGEAULT, A. Les causes de la mort : Historie naturelle et facteurs de risque, Paris: Vrin, 1989.

FOUCAULT, M. Vigiar e Punir. Petrópolis: Vozes, 1983.

LEMOS, A. "A arte da vida: diários pessoais e webcams na Internet", In CD-ROM da XI Compós, 2002.

GARZA, G. "The Internet, narrative, and subjectivity", In Journal of constructivist psychology, 15, 2002.

LYON, D. The electronic eye: The rise of surveillance society. Cambridge: Polity Press, 1994.

LYON, D. (org.) Surveillance as social sorting: Privacy, risk and digital discrimination. London: Routledge, 2003.

MARX, G. T. "What's new about the 'new surveillance'? Classifying for change and continuity", In Surveillance \& Society 1 (1), 2002.

McNEIL, L. "Teaching an old genre new tricks: the diary on the Internet", In Biography 26.1 (winter 2003).

MILLER, J-A. "A máquina panóptica de Jeremy Bentham", In SILVA, T. T. (org.) O Panóptico. Belo Horizonte: Autêntica, 2000.

NORRIS, C. \& ARMSTRONG, G. The maximum surveillance society: The rise of CCTV. Oxford: Berg, 1999. 
POSTER, M. The second media age. Cambridge: Polity Press, 1995.

ROSE, N. "Government and control", In British Journal of Criminology, 40, 2000.

SIBILIA, P. "Os diários íntimos na Internet e a crise da interioridade psicológica", In CD-ROM da XII Compós, 2003.

VAZ, P. \& BRUNO, F. "Types of self-surveillance: from abnormality to individuals 'at risk'", In Surveillance \& Society 1 (3): Foucault and Panopticism revisited, 2003.

ZUERN, J. "On line lives: introduction", In Biography 26. 1 (winter 2003). 